\title{
INSIGHTS
}

\section{In Memoriam Prof. Dr. Dr. h.c. Klaus Philipp Riegel- Leading Pediatrician, Clinical Scientist, and Pioneer Perinatal Epidemiologist}

\author{
Charles C. Roehr ${ }^{1}$ and Hans Versmold ${ }^{2}$ \\ Pediatric Research (2018) 84:570-571; https://doi.org/10.1038/s41390-018-0136-3
}

We are grieved by the loss of Professor Klaus Philipp Riegel, an exceptional champion of Pediatrics, and a gifted artist and musician alike. Klaus P. Riegel was born on May 14th 1926, in Schondorf, Swabia, southern Germany. In 1954, he married his wife Elsbeth, with whom he shared his life and the love for their children, Stephan $\left({ }^{*} 1956\right)$ and Angela $\left({ }^{*} 1958\right)$. He passed away on June 4th 2018 in Munich, Germany.

\section{(Klaus Riegel, ink drawing, 2016)}

Klaus P. Riegel has had an outstanding career. He dedicated his life to the advancement of medicine, in particular, the study of human Physiology, Pediatrics and Perinatal medicine. Riegel studied medicine at the renowned German University of Tübingen, qualifying with a medical doctorate in 1952. Following his foundational medical education, he chose to specialize in Pediatrics and trained at the Departments of Pediatrics of the Universities of Freiburg (chairman Professor N. Nitschke) and Tübingen (chairman Professor K. Betke), and at the Department of Physiology (chairman Professor H. Bartels) in Tübingen. Riegel had a brilliant scientific mind: His earlier work focused on oxygen transport and the function of fetal hemoglobin. His scientific and academic credentials cumulated in the Habilitation, the highest post-doctoral academic degree in Germany, by which he became faculty member of the renowned Eberhard Karls University of Tübingen in 1963. Through further careful and meticulous study, he began to make a name for himself as an excellent, soon worldrenowned, researcher. He worked as a NIH Research Associate at Harvard Medical School (1964-1965) with Clement A. Smith and Nikolas M. Nelson on the physiology of the newborn infant. In 1967, he followed his teacher Professor Klaus Betke to the Department of Pediatrics, University of Munich, where he directed the Division of Neonatology after being promoted to Professor of
Pediatrics in 1969.

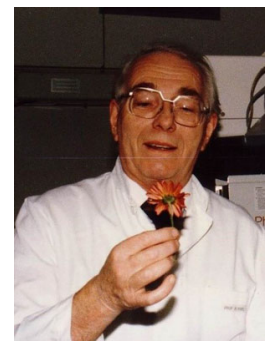

(Klaus P. Riegel. Foto: H. Versmold, with permission)

His excellence in research and recognition as an influential scientist in his field was mirrored by numerous leading roles in scientific societies, honorary memberships and awards: He was President (1984) of the European Society for Paediatric Research (ESPR), President of the German Society of Perinatal Medicine (1981-1983), honorary member of the Society for Perinatal Medicine of the GDR, and of the Bavarian Society of Obstetrics and Gynecology, member of the German Society of Paediatrics, the Society of Neonatology and Pediatric Intensive Care, and the German Society of Gynecology and Obstetrics. Further, he received numerous national and international highly prestigious awards: He was elected reviewer of the Deutsche Forschungsgemeinschaft (DFG) (1980-1984), received the Arvo Ylppö-Medal, the International Maternité-Prize, the Komtur-Cross of the Order of the Finnish Lion, was awarded an Honorary Doctorate of the Free University of Berlin, and received the Cross of Merit on Ribbon of the Order of Merit of the Federal Republic of Germany (1993) for the advancement of the quality in perinatal medicine.

To the international Pediatric community, Klaus Riegel will be very fondly remembered as Klaus Riegel the scientist, Klaus Riegel, the Pediatrician, and Klaus Riegel, the father of Quality Control in perinatal medicine. These three phases and his personality shall be highlighted below in the form of quotations by his colleagues and friends. But firstly, let's hear Klaus Riegel's own commented on his curriculum vitae, which characterizes his unique character, his kindness and humility: "There is nothing worth mentioning, except the fact that I was always lucky. Luck I had with my teachers... But really my luck began when I met Elsbeth."

As a scientist, Klaus Riegel has made major contributions to the field of Physiology. His main interest, oxygen transport from

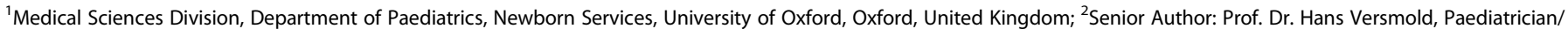
Neonatologist Klingsorstr, Berlin 9712203, Germany

Correspondence: Charles C. Roehr (charles.roehr@paediatrics.ox.ac.uk) or Hans Versmold (hans.versmold@charite.de)

Received: 13 July 2018 Accepted: 31 July 2018

Published online: 3 October 2018 
mother to fetus, remains a hot topic until this day. Here, Klaus Riegel, Enno Kleihauer, Klaus Betke, and Heinz Bartels provided invaluable elementary research. His friend at Harvard, Nick Nelson fondly reflected on their joint time at Harvard Medical School: "Klaus was exceptional in all ways. In the famous "Clement Smith Family Tree of Neonatal Research", he is at the upper right ... He was, above all, a gentleman.... A gently extroverted and extremely warm personality - and a gourmet who introduced me to "Bärlauch" \{wild garlic\}." Riegel, since his times in Boston, had kept his beloved Harvard chair, which he used until his very last days, although eventually without his tobacco pipe.

On the clinical floor, Klaus Riegel was an exceptionally gifted Pediatrician and Neonatologist, and an outstanding teacher. His ethical principle was "to avoid excessive intensive care if it would not help the infant". He detested the wide spread (presumptively) "heroic intensive care medicine (at all costs)". In his practice and tuitions, he always very clearly differentiated between "those who turned buttons at machines, and those who knew why". His unique personality as a Pediatrician is best summarized by a quote by his mentor Klaus Betke, who once described him as "musician, artist, poet of joyful verses, scientific curiosity-put it all together and you have a wonderful Pediatrician. You have the whole Riegel: artistic quality, combined with a skilled hand and the gift of sharp observation".

Indeed, Klaus Riegel did not simply accept the fate of a sick infant, but would always ask: "What are the reasons for a baby dying?" Thus, we have arrived at the third and possibly most important focus of his work: Quality control in perinatal medicine and therefore honoring Klaus Riegel who is known to many of us as the father of Perinatal Surveys. Klaus Riegel has transformed our understanding of perinatal mortality and the interdisciplinary work between Obstetricians and Pediatricians/Neonatologists. Riegel facilitated a fulminant change in interdisciplinary culture in perinatal medicine, where, prior to his immense body of work in this field, an Obstetrician faced with an infant's death would incriminate the Pediatrician, and, vice versa, the Pediatrician would incriminate the Obstetrician. Klaus Riegel in his modest and kind way has broken this icy cycle of blame, opened it up to a field of objective debate and created a culture of mutual confidence and bi-lateral understanding.

From this confidence resulted, together with the epidemiologist Professor H.-K. Selbmann, a unique interdisciplinary cooperation of quality control in perinatal medicine, first evidenced by the "Münchener Perinatalstudie" (1975), followed by the "Bavarian Perinatal Survey" (1979), the "Arvo Ylppö-Study" (1979-1982) and finally the "Study of Quality on Life of previously Premature Infants" (1984-1992). The importance of this work was pointed out by Betke, stating that "Several thousand Bavarian newborn infants were thus saved from death" through Riegel's work. The concept of quality control was soon adopted throughout Germany. His work as father of the Perinatal Surveys certainly was Riegel's greatest achievement for the society in our country. Fittingly, the Federal Cross of Merit, which he received for these achievements, was commented by Riegel: "This was of course a great honor, but really proud I was when I was elected member of the venerable Leopoldina, the German Society of Natural Sciences". Another highlight was remembered by Professor Osmund Reynolds from London. As president of the ESPR, Klaus P. Riegel had organized a most successful meeting in Munich in 1985. Reynolds said: "wonderful was his farewell speech: ingenious, critical and selfcritical limericks". Undeniably, the unique gifted Riegel had succeeded in creating an unforgettable, truly European atmosphere.

Summarizing the outstanding personality of Klaus Riegel, we would like to finish with a quote by Professor Betke: "Klaus Riegel is a universal genius, a brilliant artist, an excellent cello player, an exact scientist and an empathic, caring, admirable physician; all this embedded in a broad general education. At the same time he has a critical humor. We got along very well. ... Our common work turned into a cordial friendship". This is how we would like Klaus P. Riegel to be remembered. As we are most grateful for his extraordinary leadership and achievements as much as for his warm, modest and generous personality, our thoughts and warm wishes are with his wife and family. 